\title{
Rational Exploration on the Morning Exercises System in Regular Institutions of Higher Learning in Viewpoint of Humanistic Care
}

\author{
Jing Li \\ Wuhan Technology and Business University \\ Wuhan, China
}

\author{
Lifen $\mathrm{Hu}$ \\ Wuhan Institute of Bioengineering \\ Wuhan, China
}

\begin{abstract}
The thesis, through such methods as field visiting, searching for documental literature and interviews, etc., makes deep survey on the intractable current situations of launching morning exercises activities in colleges and universities and conducts a specific analysis on the impersonal restricted factors, so as to come up with some concrete suggestions on fulfilling multi-aspect and comprehensive morning exercises system from the aspect of humanistic care and based on the characteristics of the new-generation students and under the guidance of the 17th CPC National Congress's concept "people oriented".
\end{abstract}

Keywords—put students first; morning exercises; exploration

\section{INTRODUCTION}

It has been pointed out in the Report of the 17th National Congress of CPC that we have to lay emphasis on freedom \& equality, fairness \& justice and pursue to achieve everyone's interests on the basis of the common benefits of the national people, so that it can give expression on socialistic humanism and humanistic care that we must respect and protect human rights and further to realize person's integrated development.

As an educational institute, we are supposed to advocate to "put students first" since students are a major part of the masses. "Put students first" is a specific expression of "people oriented" in schools" education which requires more "humanistic care" in education and students should be treated as real and lively individuals who have thoughts, feelings, rights and dignities, who are in their growth and development which will eventually form completed persons. That is to say, teachers are required to fully respect students' humanity, personality and personal rights and provide them with more trusts, understanding and tolerance so as to establish humane, harmonious and democratic relations between students and teachers. On the other side, schools are necessary further to convert their concepts on managing students on various sides and consider "serve students" as the primary need, take students' maximum benefits as the basis and preserve in all kinds of humanistic care for management.

Fund program: Scholl-level Teaching \& Research Subject: Teaching Design and Practice on College Sports "Turnover Class"-Taking Cheer Leading Course Teaching as Example, Fund No.: $2016 Z 07$.

\section{ORIGIN AND CURRENT SITUATION OF OUR NATIONAL SCHOOLS' MORNING EXERCISES SYSTEM}

\section{A. Origin of Schools' Morning Exercises System}

In the 1980s, Ministry of Education issued Physical Training Standard for College Students which stipulated that college students must do morning exercises. Following constantly increasing enrollment and gradually deepening reform of students' management, various changes have taken place on the morning exercises' contents and forms of each college or university. However, it has been discovered by investigation that morning exercises activities in many colleges and universities exist in name only which become formalistic and perform practically no function. In April 2007, Ministry of Education and State General Administration of Sports and sports departments in different levels initiated "sunshine sports" and with the development of the activity, such slogan "doing exercises one hour in every day can enable you healthily work for 50 years and be happy forever" is widely known by the public. As a result, "sunshine sports" activities are being carried out by diversified forms and styles around the country. Nevertheless, morning exercises has been making physical educators stuck in dilemma because the old morning exercises system has been no longer suitable for the newgeneration students, and it is in dire need that exploring an applicable morning exercises method to satisfy students' characteristics so as to effectively improve their sports attainment and intensify their lifelong sports awareness.

\section{B. Current Situation of Schools' Morning Exercises System}

Different methods of managing morning exercises in colleges and universities crease diversified activity contents and styles of morning exercises. Furthermore, the current situations of morning exercises in different colleges or universities can be classified to the following three types: one is that there are no more requests for students to do morning exercises and schools just left things drift; the second situation is that schools take hard-and-fast rules to force students to do morning exercises and strictly conduct roll call which directly links up with students' sports performance, graduation and appraisal. Obviously, the disadvantages of this method are that it may possibly make morning exercises play false and become formalistic; finally it not only cannot realize the goals and 
effects of doing morning exercises but causes a waste of time, so that the loss outweights the gain. The third one is in some schools who have done a relatively excellent work, schools and teachers have put into large number of time, energy and materials, etc. which may bring some effects but still get the half result with the twice efforts and cannot achieve a satisfactory result.

\section{Opposite Attitudes of Experts and Scholars forWhether Morning Exercises is Continuned}

The consistent opinion of whether to carry out morning exercises activities or not has not been reached by physical educators and a majority of physical scholars. Whereas, most scholars still support to launch morning exercises activities in their literatures and they believe that morning exercises has significant meanings to the construction of campus culture and standardization of school spirits, formation students' good life habits and practice on lifelong sports. On the contrary, part of documental literatures of many scholars have indicated the necessity of reforming the mode and management system of morning exercises, such as the scholar Wang Wenzhong has proposed to abolish morning exercises system since there are great changes in students' life styles that they cannot keep early hours due to the influences of modern life style; moreover, the poor air quality and lack of sleep also became the reasons of canceling the morning exercises system.

The first-tier physical teachers have been suffering from no sound strategy on morning exercises system; meanwhile the opposite opinions among physical experts and scholars have been the problems of whether or not continuing the existing morning exercises system which are in dire demands for being solved by us through properly managing morning exercises order and combining with students' characteristics to arrange applicable exercises.

\section{ANALYSIS OF IMPERSONAL RESTRICTED FACTORS OF IMPLEMENTING MORNING EXERCISES SYSTEM IN COLLEGES AND UNIVERSITIES}

\section{A. Single and Simple Contents of Morning Exercises Which Fail to Satisfy the Demands of Students' Personality Development}

Single and simple exercises contents have given rise to students' inimical emotions. Therefore, it is necessary for us to take efforts to formulate exercises outlines suitable for the school's conditions on the basis of teenagers' laws in physical and mental development and comprehensively considering of the actual situations of school's faculty, fields and facilities, etc. In addition, schools should take fully consideration of students' physiological and psychological demands to enlarge the scope of choices on new outline contents so as to meet students' requirements for the curiosity and desire for seeking knowledge on brand-new objects. Moreover, the outline to be formulated must be able to integrate the stipulated contents and independently chosen activities as well as combine scientific nature and effectiveness; also it is supposed to appoint professional and skillful physical educators to guide physical training and satisfy diversified interests and requirements for sports of students.

\section{B. Morning Exercises Forms Being Meaningless for Sports Training Goals}

Exercises in various styles can be carried out by each class such as events of team competitions in playing football, basketball, volleyball and track and field, or other events of personal competitions in badminton, ping-pong and tennis, etc. Moreover, some team events like martial art, free combat, taekwondo, dance and gymnastics can be launched by selfselected group. Those diversified morning exercises activities can not only increase students' interests in morning exercises but enhance their sense of team honor.

\section{Shortage of Schools' Fields and Funds}

Only several thousand funds are used for carrying out morning exercises activities of schools every year, and there are less are used for rewarding excellent student leaders and outstanding classes. Small-scale rewarding has lead to the low enthusiasm of students to behave well. Besides, various reasons have caused schools fail to provide students with gymnasiums for conducting morning exercises activities, so that they can only run around several sections of teaching buildings, which greatly limited activity items and reduced students' interests in morning exercises.

\section{Complex Organization and Management}

With the enrollment expansion of colleges and universities, popularities in regular institutions of higher learning have been rapidly increased and there are several thousand students in only one class, even there are several thousand students in some hot majors. It has to take a while to collect those students, so obviously it becomes more difficult or even impossible to collect all students to do morning exercises and reach the effects of keeping health. In a usual way, it almost needs to dismiss after gathering. Secondly, due to large number of students, it brings a huge problem on selecting sports events, organizing team and choosing fields and equipment to school's physical education groups.

All sorts of impersonal restricted factors result in the impossible implementation of morning exercises in colleges and universities and further make negative influences on students' feelings attending morning exercises. Surveys' results have indicated that most students believe attending morning exercises in schools is only for coping with checking attendance, while few students are really on the purpose of invigorating health effectively. Besides, under the strong influences of the organizing styles, contents and fields of morning exercises, students cannot automatically form the awareness that persisting in doing morning exercises is an effective way to keep physical health, even under the incorrect motivation, on the one hand, they cannot achieve good effects from morning exercises. On the other hand, they will gradually form a shadow realization on sports and cannot deeply understand the real meanings of exercises; besides, they will have poor exercise ability and may inordinately generate a sense of contempt on sports. 


\section{CHARACTERS AND PSYCHOLOGICAL DIFFERENCES OF THE NEW-GENERATION STUDENTS}

\section{A. Rebel Psychology of Adolescent Students}

Not only vitality and energy but all kinds of conflicts and contradictions are full with the hearts of adolescent students, so it manifests the dire demands of independence of them, which is, they desire to get rid of adults' restrictions. Having suffered from studying for so many years, they finally arrive in the Ivory Tower of freedom, and it is no doubt that compulsory morning exercises are a kind of pressure for most students. Thus, when facing up with the gap between reality and the ideal life in the Ivory Tower, students tend to choose escaping and rebellion.

\section{B. Inaccurate Understanding on Their Existing Meanings and Positions}

Under the background that the overwhelmed information in the network age has brought rapid development in thousands of high-techs, students hardly formulate accurate positioning on themselves, and such words as "hard-working, diligent and persistent" seemingly no longer signify an appreciative meanings; meanwhile, other words like "new, artful and clever" which refer to gain "success" by scientific and technological measures enjoy more popularity among students. Such a morbid psychology has caused that many students began to play "tricks" on study, so that they overvalue themselves and cannot realize where their true meanings and positions lie in.

\section{Postponed Internal Clock Impacting Work and Rest Habit}

It is extremely common that the new-generation students keep late hours which is required to be immediately adjusted for attending morning exercises. To overcome the healthy internal clock requires powerful self-control abilities which, for those college students just fulfilling their independence and self-supporting, undoubtedly becomes a major factor that keeps students from getting up earlier and doing morning exercises when their unhealthy internal block has been formed for a long time and when their expectation and desire on a comfortable college life exist.

\section{D. "Conformity" Idea}

With respect to unsophisticated older generation, the newgeneration students usually have more sharp-witted characters, "conformity" idea is quite common among students since "going with the tide" and "following the general trend" may bring more sense of security for them when dealing with some events. There are few students positively participating in morning exercises activities, so it is difficult to form leading influences.

\section{EXPLORATION ON MORNING EXERCISES SYSTEM BASED ON HUMANISTIC CARE}

Morning exercises can not only invigorate health effectively but give assistance to them for forming good work and rest habits. However, there are lots of difficulties for realizing the goal of getting up early for doing exercises. As the new-generation college students, we, during the important phase of growing in body, increasing in knowledge, coming of wisdoms and completing in psychological abilities, should be under considerate concerning of "put students first". That is to say, schools are supposed to make corresponding adjustment on managing morning exercises for meeting the newgeneration students' personalities and psychological characteristics to enable students to positively manage their exercises instead of negatively receiving schools' stipulations and gradually form the good habit to voluntarily do exercises mainly through the following ways:

\section{A. School-level and Faculty-level Clubs Popularizing Morning Exercises Culture}

Various clubs can enable students to comprehensively and exactly understand all kinds of deep culture of morning exercises by sorts of popularizing methods such as promotional prints, knowledge lectures and group discussion, etc. and under effective assistant roles of changing physiological, mental and personal habits to make morning exercises culture penetrate into people's heart so as to form their healthy life styles.

\section{B. Systematizing the Large-Scale Morning Exercises Content Classification}

The new-built morning exercises system should enrich the original contents which only signifies running and set some fashionable sports special projects such as street dancing, roller skating, parkour and social dancing, etc. which may be trained by professional teachers according to the characteristics of the new-generation students. Furthermore, the contents can be systematized on the basis of students' whole situations so as to enable them to acquire their interested knowledge, indeed.

\section{Principle of Voluntariness, Hierarchical Planning on Morning Exercises Contents}

Schools are suggested to set morning exercises centers of school-level and each faculty or department levels, separately. The school-level morning exercises center mainly provides students with supports and convenience to voluntarily apply for participating in collective exercises aiming at teaching and training of different sports events; those students who do not participate in school-level morning exercises center are supposed to attend their faculty's morning exercises center whose contents are applicable for the faculty's specialty and satisfy their professional demands.

\section{Sound Organization and Management System}

A five-level agreement organization, including five classes of students union, instructors (teachers in charge), physical education department, office of teaching affairs and school's leaders, and by their harmonious coordination and operation, they can take competent responsibilities for building up a uniform morning exercises system so as to supervise and urge students to positively participate in morning exercises. 


\section{E. Quantitative Inspection Appraisal System}

The system is mainly to inspect and assess morning exercises centers of each department or faculty, also publish the assessment results on some aspects including students' attendance ratio, discipline and structure, morning exercises' quality and effectiveness and so on as one of the final examination contents of each department or faculty.

\section{CONCLUSION}

Morning exercises are one of the key links in schools' education and also a long-term hard work. To perfectly complete the work, we are not only required to make longterm and rigor arrangement and establish specific and concrete management system and strict and impartial rewards and punishment system, but aim to satisfy the new-generation students' characteristics by arranging targeted and interesting morning exercises which are able to follow the interests and fashions of the new-generation students and get acquaintance with students' ideological states by making macro-adjustment on education methods and modes that are in line with students' growth environment and carry with humanistic care as well as "put students first". By that way, it is likely for schools to intensify to guide and bring into full play on subjective initiative of students and eventually promote students to form good health maintaining habits of abiding by school disciplines and having everyday physical morning training by their selfawareness.

\section{REFERENCES}

[1] Cheng Li. Reform on the Current Morning Exercises System in Colleges and Universities, Friend of Sports, 2006.3.

[2] Zhang Pingbo. Problems and Countermeasures of Morning Exercises' Current Situations of Vocational College Students, Journey of Xiangfan Vocational and Technical College, 2009.8.

[3] Yang Yingtian. Analysis and Countermeasures of Current Situations of Regular Institutions of Higher Learning's Morning Exercises, Journey of Jinzhou Teachers Training College, 2002, 23.

[4] Wu Xiaozhen. Current Situation Analysis and Countermeasure Research of Morning Exercises in Colleges and Universities [J] Journey of Fuyang Teachers College, 2005 (3): 80 83.

[5] Zhang Xiaojie, Li Kelei. Exploration and Discussion on Methods of Reforming Morning Exercises System in Our City's Regular Institutions of Higher Learning [J]. Journey of Chengde Teachers College for Nationalities, 2004.5 (24) (2) 75-76.

[6] Wang Fenghai. Morning Exercises' Meanings on Campus Culture [J]. China Science and Technology Information, 2005, (15): 267

[7] Xiang Jianmin, Gong Wanmin. Methods and Features of Garden-style Morning Exercises [J]. China School Physical Education, 1997, (05): 116-117 